\title{
Whole person care: encompassing the two faces of medicine
}

"I would go without shirt or shoe Friend, tobacco or bread, Sooner than lose for a minute the two Separate sides of my head!" - Rudyard Kipling, The Two-Sided Man

$\mathrm{W}$ hat is Kipling talking about and what, if anything, does it have to do with medicine? Actually, it lies at the heart of our current problems and opportunities in medicine: we have lost and are trying to regain one of the sides of our medical heads. That is what physicians Michael Kearney and Balfour Mount ${ }^{1,2}$ are pointing out when they ask us to reincorporate healing into the medical mandate. But we have not yet explored adequately and don't yet understand fully the difficulty of what they are calling on us to do. Curing and healing are like the 2 faces of Janus, the Roman god of gateways and new beginnings. They are antipodes and yet both are simultaneously essential to excellent medical care.

Curing is an action carried out by the health care practitioner to eradicate disease or correct a problem, ${ }^{3}$ while healing is a process leading to a greater sense of integrity and wholeness in response to an injury or disease that occurs within the patient, which can be facilitated by the health care practitioner. ${ }^{2}$ The roles of the patient and of the health care practitioner in curing versus healing are not just different, they are diametrically opposed.

The goal of the patient in the curing mode is survival. This is not limited to physical survival; rather it extends to survival of all that the patient has learned to identify as himself, including physical appearance, lifestyle, relationships and everything else that makes up a life. In other words, the goal is to avoid change. Healing, on the other hand, comes from the acceptance of change. This acceptance allows the patient to grow to a new sense of himself as a person (perhaps

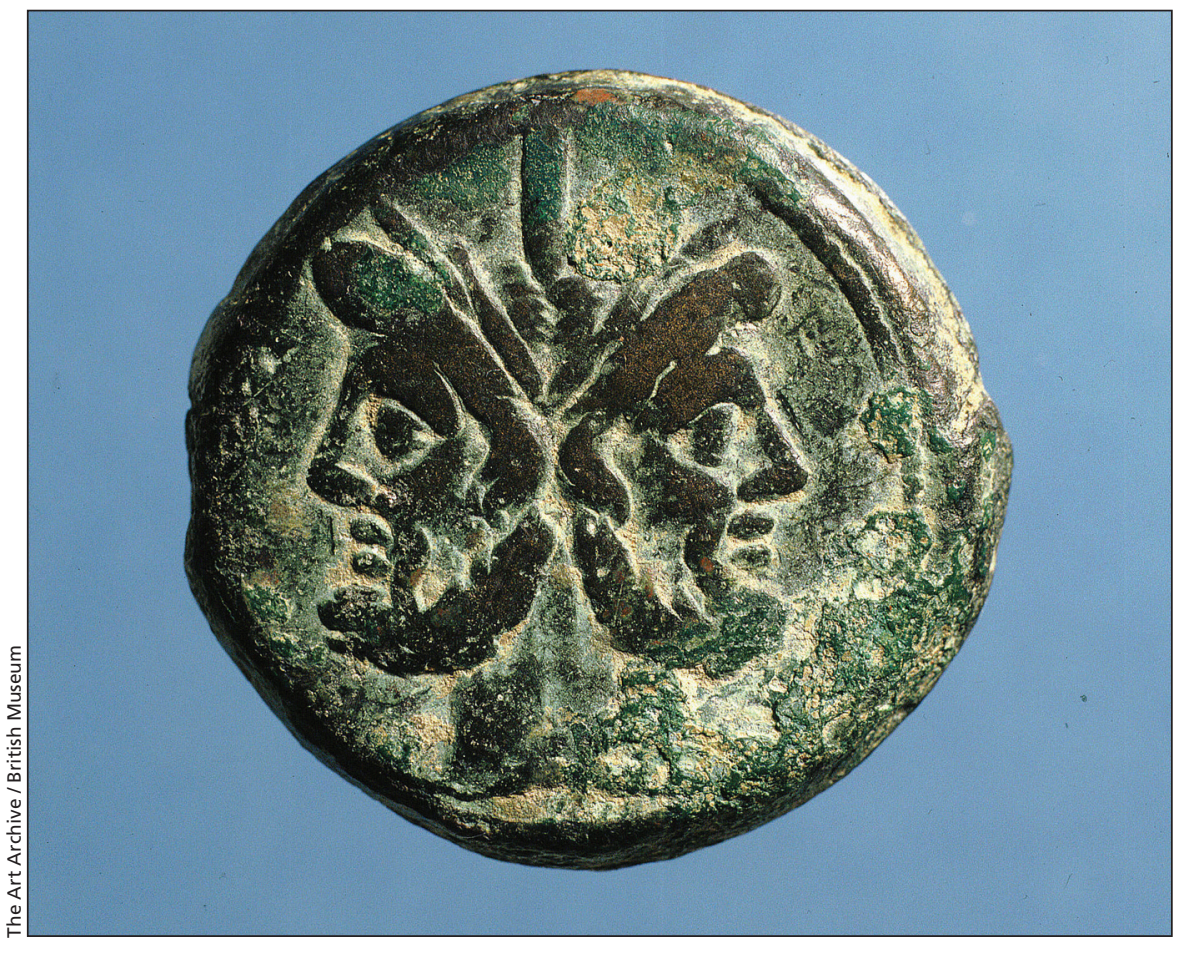

Janus, the Roman god of doorways, looks in 2 directions. Likewise, physicians are charged with looking toward both healing and curing. (Bronze coin of Janus, 211 BC.)

with disease) with a new experience of integrity and wholeness that is different than the old status quo. In curing, the patient depends on the expertise of the practitioner to control disease; in healing, the patient begins to realize that it is his or her own resources that will finally lead to growth and that he or she is responsible for managing those resources.

The contrast in the health care worker's roles in curing and healing are equally striking. In the curing mode, the physician, through his knowledge and expertise concerning disease, clearly has more power. That is why the patient consulted him in the first place. In the healing mode the power shifts toward the patient. It is within the patient that healing will occur and it is the patient who will make the healing journey. The physician's role is accompaniment. To do this effectively the physician needs to be able to put part of himself in the patient's shoes and thus adopt the wounded healer role. ${ }^{4}$

The epistemologies in the curing and healing roles are also very different. In the curing mode the basis of knowledge is scientific and this is expressed in the current requirement of evidence-based practice. In the healing mode this approach is not helpful. Since the essence of the facilitation of healing is the relationship of one person to another, the physician's role in healing has to depend on his particular gifts and characteristics as a person and on the particular gifts and characteristics of the patient. Art rather than science is required to enable the physician to make the best intuitive use of himself in the healing relationship with the patient. The dynamics of the interaction would be different with every physician-patient pair, a complete 
contrast to the standardized requirements of science.

Given the contrasts outlined it is not surprising that physicians and other health care workers have had a hard time encompassing both roles in their practice. The solution is often to restrict care to 1 of the 2 poles, curing or healing, but not both. awareness when we are faced with stressful situations. ${ }^{5}$

Physicians and other health care workers need to relearn ${ }^{1}$ an important skill: how to retain a broad enough awareness to encompass simultaneously the needs of both curing and healing in stressful clinical situations. We might hope that this is the purpose of teaching

\section{To be an effective curer and facilitate healing at the same time is a challenging task.}

To be an effective curer and facilitate healing at the same time is a challenging task: this patient may be dying and I must remain emotionally present to that possibility and behave and communicate with the patient and family accordingly; at the same time, I must concentrate on inserting this femoral catheter so that we can perform the dialysis to treat his acute renal failure and possibly save his life, at least for now.

As may be apparent from this example, the enlargement of awareness required is significant, but can actually result in a decrease in the psychological tension that comes from identifying exclusively with curing or healing. However, our tendency is to restrict hospitals and clinical clerkships where students can see this process in action in a clinical setting. This does undoubtedly occur, but because medicine itself is unclear about these 2 roles and has tended to opt for curing at the expense of healing $^{3}$ we have found that students' experiences in hospital can hinder, rather than foster their development as facilitators of healing. ${ }^{6}$ It is not only students, but faculty as well who need to learn how to encompass these 2 roles.

We believe that the key lies in bringing clarity and commitment to these 2 complementary aspects of medical care. We at McGill are exploring various approaches, including a focus on mindful medical practice ${ }^{7}$ and a new 4-year healing curriculum ${ }^{8}$ to foster the healer role. In this way, the gateway to what we term whole person care may be fully reopened in the context of sophisticated 21 st century biomedicine.

\section{Tom A. Hutchinson MB}

Director

McGill Programs in Whole Person

Care

Nora Hutchinson BA

Faculty of Medicine

Class of 2012

Antonia Arnaert PhD

Assistant Professor

School of Nursing

McGill University

Montréal, Quebec

\section{REFERENCES}

1. Kearney M. A place of healing: working with suffering in living and dying. Oxford (UK): Oxford University Press; 2000

2. Mount B, Kearney M. Healing and palliative care: charting our way forward. Palliat Med 2003;17: 657-8

3. Cassell E. The healer's art. Cambridge (MA): The MIT Press; 1976.

4. Guggenbühl-Craig A. Power in the helping professions. Dallas (TX): Spring Publications; 1971.

5. Driskell JE, Salas E, Johnston J. Does stress lead to a loss of team perspective? Group Dyn Theory Res Pract 1999;3:291-302.

6. Allen D, Wainwright M, Mount BM, et al. The wounding path to becoming healers: medical students' apprenticeship experiences. Med Teach 2008;30:260-4.

7. Epstein RM. Mindful practice. JAMA 1999;282: 833-9.

8. Boudreau JD, Cassell EJ, Fuks A. A healing curriculum. Med Educ 2007;41:1193-201.

\section{REVIEW}

\section{Art is science made clear}

$\mathrm{M}$ edical humanities visual arts have come of age in Canada through a special double issue of RACAR: Revue d'art canadienne/Canadian Art Review (2008:33 [1-2]), which provides a well-rounded mélange of 8 scholarly papers and 7 contemporary Canadian artists' projects.

These 2 parts inform and build on one another in, "Medical Tabulae: Visual Arts and Medical Representation," which is ably guest edited by Allister Neher and Mireille Perron.

The scholarly papers explore art and anatomy in the 19th century and more recent artistic representations of the medical aesthetic. Written for an academic audience - the journal is, after all, the official publication of the Universities Art Association of Canada the prose is sometimes quite laden by that queer variation of the English language: art-speak. Nonetheless, if you peel back the layers, the discourse is quite interesting.

The 3 historic papers delve into artistic representations of medicine such as the seemingly objective beauty of wax models, the human dimension of the anatomical atlas and an interesting arti- cle on Sir Charles Bell (1774-1842), who made the science of anatomy and neurology accessible to artists striving to depict natural-looking bodies.

Four other scholarly essays look to the work of more contemporary artists. Of particular interest are Andres Serrano's controversial series of Cibachrome prints, The Morgue (1992), which depict unnamed corpses at an unspecified morgue. Author Andrea D. Fitzpatrick writes that Serrano's work has been aligned with the "renaissance and Baroque anatomy theatres where a subject's criminal status 